\title{
Radial blast prediction for high explosive cylinders initiated at both ends
}

\author{
A. C. Anastacio, ${ }^{*[a]}$ C. Knock $[b]$
}

\begin{abstract}
This paper presents experimental results for the double ended initiation of cylindrical, explosive charges. Bare cylindrical charges of PE4 (RDX/binder $88 / 12 \%$ ) were used with length to diameter ratios of ratios of $1 / 3.7$ to $5.75 / 1$ and masses of 0.25 to $0.45 \mathrm{~kg}$. Pressure measurements were taken at distances of 1 to $3.5 \mathrm{~m}$ in the radial direction. It was found that it was possible to predict the peak overpressure in the radial direction using $P=K^{\prime} M(L / D)^{1 / 3} R^{-3}$. $M$ is the mass of explosive, $L$ the length of the explosive charge, $D$ the diameter of the explosive charge and $\mathrm{R}$ the distance from the charge. For $\mathrm{PE} 4, \mathrm{~K}^{\mathrm{N}}=2251 \mathrm{kPa} \cdot \mathrm{m}^{3} \mathrm{~kg}^{-1}$ for all length to diameter ratios. The double ended initiation gives a peak overpressure 1.6 times that for single ended initiation. The impulse for double ended initiation was found to be the same as for single ended initiated charges.
\end{abstract}

Keywords: Cylindrical Charges, Peak Overpressure, Blast Prediction, Impulse, Double Ended Initiation

\section{Introduction}

Most data available for predicting the shock waves from an explosion are based on spherical charges $[1,2]$. However, warheads generally have a cylindrical shape.

Cylindrical, high explosive charges produce more complex blast fields compares to spherical charges, especially close into the charges [3,4]. This can result in multiple shockwaves with the peak overpressure of secondary shock waves sometimes exceeding that of the primary shock waves [5].

The shape of the blast wave also depends on the position and number of points of ignition [6]. Hence to be able to predict the effects of an explosive charge it is essential to understand the effects of the number of ignition points on the production of shockwaves.

This paper looks at the effect of multiple ignition points on the shock waves produced from cylindrical charges. New experiments were carried out detonating cylinders and discs of high explosive. The charges were simultaneously detonated from two points. One detonator was placed at the centre of each flat surface at the ends of the cylinder, as shown in Figure 1, known as double ended initiation. The overpressure from the curved surface is measured and the impulse and peak overpressure compared to literature data for a single point ignition.

\subsection{Single point end initiation}

Past work on the blast waves from cylindrical charges initiated at one end indicates that the blast wave is not the same in all directions [3-5,7-10]. Instead multiple shock waves are seen in the direction of least presented area $[3,5]$.

Previous work $[9,11]$ has shown that it is possible to predict the peak overpressure of the blast wave from the curved surface of a cylinder at its middle plane, Line A in Figure 1. For cylinders with a length, $L$, to diameter, $D$ ratio of greater than 2 , that is $\mathrm{L} / \mathrm{D}>2$, it was found that the best prediction for the peak overpressure, $P$, was given by [9]

$$
\mathrm{P}=\frac{\mathrm{a}}{\mathrm{Z}}+\frac{\mathrm{b}}{\mathrm{Z}^{2}}+\frac{\mathrm{c}}{\mathrm{Z}^{3}}
$$

Here $Z=R / M^{1 / 3}$ is the scaled distance with $R$ the distance from the explosion and $M$ the mass of explosive. $\mathrm{a}, \mathrm{b}$ and $\mathrm{c}$ are explosive dependent coefficients. equation

Also it was found that close in, the simpler

$$
\mathrm{P}=\mathrm{K} \frac{\mathrm{M}}{\mathrm{R}^{3}}=\mathrm{K} \frac{1}{Z^{3}}
$$

can be used, where $\mathrm{K}$ is an explosive dependent coefficient [9]. The transition point was found to be at approximately $Z=3.4 \mathrm{~m} \mathrm{~kg}^{-1 / 3}[9]$.

The impulse can be predicted using [11]

$$
\mathrm{I}=\mathrm{K}_{\mathrm{I}} \frac{\mathrm{M}^{2 / 3}}{\mathrm{R}}
$$

or

[a] Aline C. Anastacio;

University of Pardubice

Institute of Energetic Materials

Doubravice 41, 53210 Pardubice, Czech Republic

Tel: + 5521979328337

E-mail: alineanastacio@gmail.com

[b] Clare Knock

Centre for Defence Engineering

Cranfield University

Defence Academy of the United Kingdom

Shrivenham

Swindon, SN6 8LA, UK

E-mail: c.knock@cranfield.ac.uk 


$$
\mathrm{I}=\mathrm{K}_{\mathrm{I}} \frac{\mathrm{M}^{0.5}}{\mathrm{R}}
$$

where $\mathrm{K}^{\prime} \mathrm{I}$ and $\mathrm{K}_{\mathrm{I}}$ are explosive dependent constants and with the data available it is not possible to determine which equation gives the best fit to the data. For PE4 K` $=145 \mathrm{kPa} \mathrm{ms} \mathrm{m} \mathrm{kg}^{-2 / 3}$.

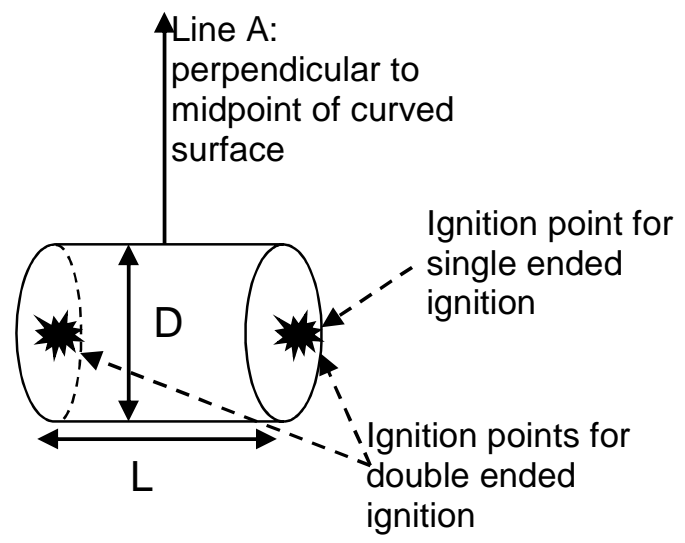

Figure 1. Cylindrical explosive charge indicating ignition points for single and double ended iniitation. D is the diameter and $L$ the length.

Further work resulted in a model for cylindrical charges for all length to diameter ratios [12]. The peak overpressure in the radial direction can be predicted by [12]

$$
\mathrm{P}=\frac{A}{\mathrm{Z}}+\frac{B}{\mathrm{Z}^{2}}+\frac{C}{\mathrm{Z}^{3}}
$$

where $A, B$ and $C$ are explosive dependent constants and $Z^{\prime}=R /\left(M^{1 / 3}(L / D)^{1 / 9}\right)$.

Again, at close range it was found that a simpler equation could be used given by

$$
P=K^{\prime} \frac{\mathrm{M}(L / D)^{1 / 3}}{R^{3}}=K^{`} \frac{1}{Z^{\prime}}
$$

where $K^{\prime}$ is an explosive dependent constant. For PE4, $\mathrm{K}^{\wedge}=1525 \mathrm{kPa} \cdot \mathrm{m}^{3} \mathrm{~kg}^{-1}$.

The impulse was found to not depend on the length to diameter ratio and so Eqn. (3) or (4) can be used for all length to diameter ratios [12].

\subsection{Multiple point initiation}

Though the charge geometry plays a major role in the blast field for high explosive detonations, the initiation point also has an influence on how shock waves are formed and interact with each other and the environment [6].

Computer modeling has been used to predict the blast field from cylindrical charges initiated with several configurations. Schraml et al [6] studied the initiation of a cylindrical charge from both ends simultaneously. The cylinder had a length to diameter ratio of 1.6/1 $(\mathrm{L} / \mathrm{D}=1.6 / 1)$. The problem was modelled using a finite element computer code. The results showed that there would be a peak of overpressure along the radial line, in the mid plane of the cylinder, line $A$ in Figure 1. The computer model results showed that the single ended initiation resulted in a lower overpressure in the radial direction than the double ended initiation [6]. From the plots given, peak overpressure for the double ended initiation appears to be up to 9 times that of the single ended initiation [6, Figure 4].

A study by [13] explored the effects of the superposition of shockwaves in water caused by the simultaneous detonation of both ends of cylindrical charges made of $50 \%$ TNT and $50 \%$ RDX. The results showed that the pressure where the shock waves met (in the centre of the radial direction of the charge, Line A, Figure 1) was double that of the pressures outside the area of collision, at the same distances from the charge.

Published work on cylindrical charges in air has either had single point initiation [3,5, 9-12] or if double ended initiated it has been at fixed L/D ratios [6]. The present work investigates the blast field generated by cylindrical charges initiated simultaneously at both ends using a wide range of L/D ratios. The aim is to verify if double ended initiation has a major effect on the blast field and if so to quantify the effects.

The work consists of carrying out new experiments to measure the pressure in the radial direction of cylindrical charges. The charges are initiated from both ends simultaneously. The data is then analyzed to determine the peak overpressure and impulse. The results are then compared to those for single end initiation.

\section{Experimental work}

To measure the peak overpressure from double ended initiation, bare cylindrical charges of PE4 (RDX/binder 88 / $12 \%$ ) were detonated and the pressure measured. The bare PE4 charges had length to diameter ratios of $\mathrm{L} / \mathrm{D}=5.75,3.55,1.95,0.99,0.55$ and 0.27 . The masses ranged from 0.25 to $0.45 \mathrm{~kg}$.

The charges were hand filled. There were three replications for each size. The standard deviation for the densities for all charges was $0.007 \mathrm{gcm}^{-3}$.

Simultaneous ignition was achieved using two strips of sheet explosive SX2 of identical lengths, attached to both ends of the charge. The detonator used was a Davydet No.8 strength electric detonator, consisting of $800 \mathrm{mg}$ of PETN in an aluminum alloy shell, and it was placed at the end of the two SX2 strips that were held together. Wires placed around the charges provided attachment to the supports 
during firing. A charge ready for the detonator to be placed in position is shown in Figure 2.

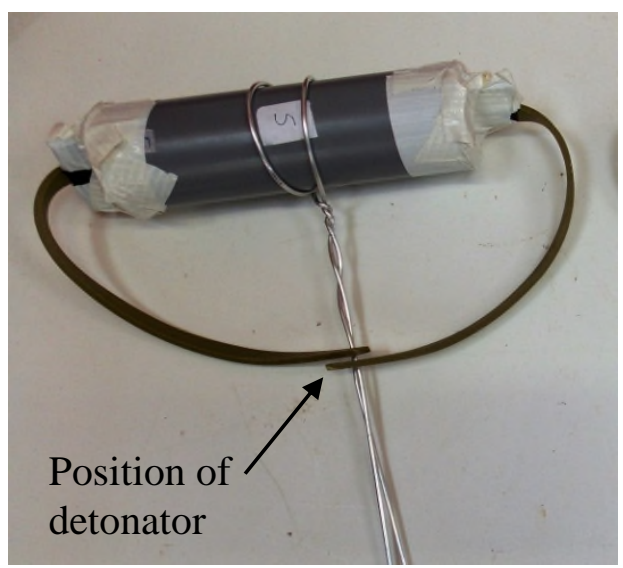

Figure 2. Prepared cylidnrical charge of PE4.

The pressure transducers used were Kistler 221B series Piezotron overpressure sensors. They were placed in the radial direction, along line $A$ in Figure 1, at distances of $1 \mathrm{~m}, 2 \mathrm{~m}, 2.5 \mathrm{~m}, 3 \mathrm{~m}$ and $3.5 \mathrm{~m}$ from the explosive charges. A single gauge was placed $1 \mathrm{~m}$ from the charge in the axial direction. More details on the experimental technique can be found in [9].

\section{Results}

The data from the pressure transducers was analysed to obtain the peak overpressure and impulse for the double ended initiated firings.

The values of peak overpressure were examined to find a relationship between peak overpressure and the mass of the charge, the length to diameter ratio of the charge and the distance from the charge.

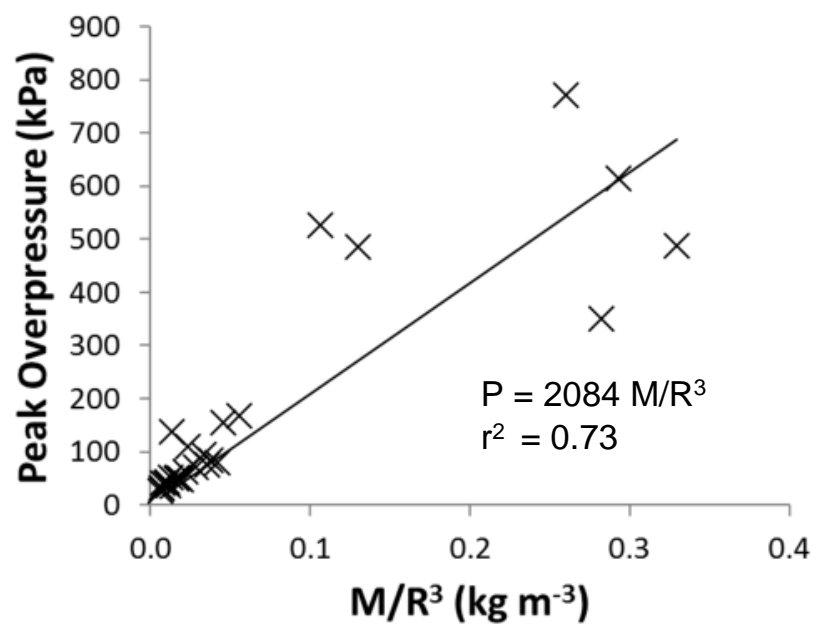

Figure 3. Radial peak overpressure plotted against $\mathrm{M} / \mathrm{R}^{3}$.
First the effect of the length to diameter ratio was neglected in trying to predict the peak overpressure. Eqn (2) was used to see if there was a correlation between the peak overpressure, mass and distance. The data was plotted and a least squares fit method used to fit a line to the data. A limited correlation was obtained as shown in Figure 3 with a correlation coefficent, $r^{2}$, of $r^{2}=0.73$.

The length to diameter ratio can be taken into account by using Eqn. (6). Using this relationship between the peak overpressure, mass, distance and length to diameter ratio gives a strong correlation, $\mathrm{r}^{2}=$ 0.95 , Figure 4. The value of the coefficient $\mathrm{K}^{\prime}$ is $\mathrm{K}^{\top}=$ $2251 \mathrm{kPa} \mathrm{m}^{3} \mathrm{~kg}^{-1}$.

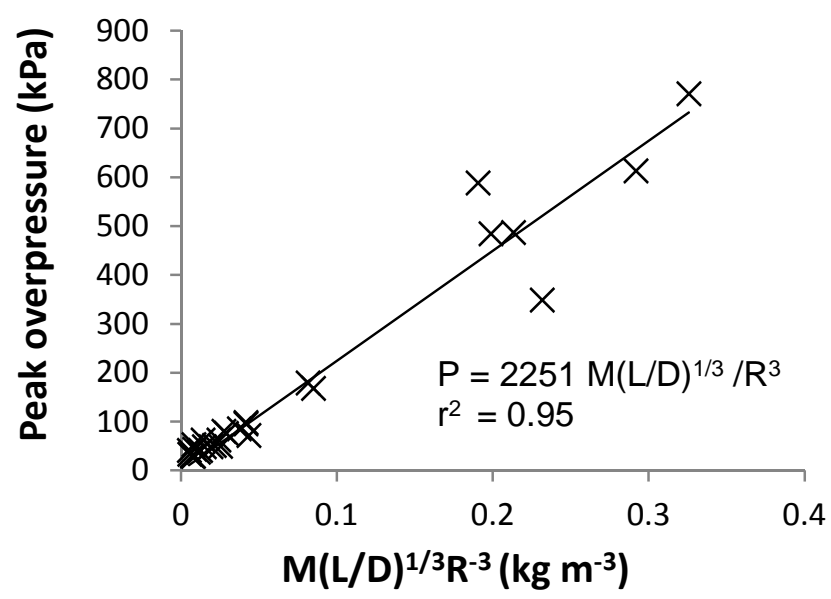

Figure 4. Peak overpressure plotted against $M(L / D)^{1 / 3} R^{-3}$

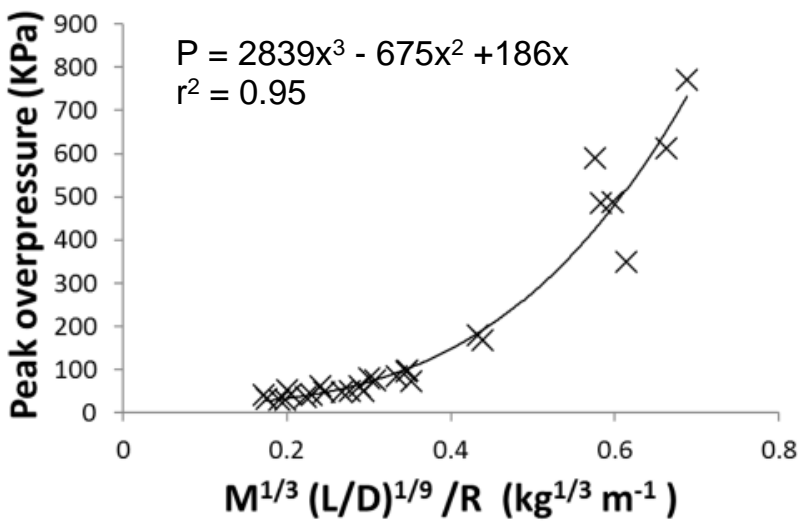

Figure 5. Peak overpressure plottted against $\mathrm{M}^{1 / 3}(\mathrm{~L} / \mathrm{D})^{1 / 9} \mathrm{R}^{-1}$.

For single ended initiation it was found that using Eqn. (6) to predict the values of the peak overpressure, the prediction was less accurate far from the charge. Instead it was better to use Eqn. (5) that applied to all distances from the charge. When Eqn. (5) was applied to double ended initiated charges, it was found that the correlation coefficient did not increase, but remained as $r^{2}=0.95$ as shown in Figure 
5 This implies that Eqn.(6) applies for all scaled distances measured, $\mathrm{Z}=1.4$ to $5.5 \mathrm{~m} \mathrm{~kg}^{-1 / 3}$.

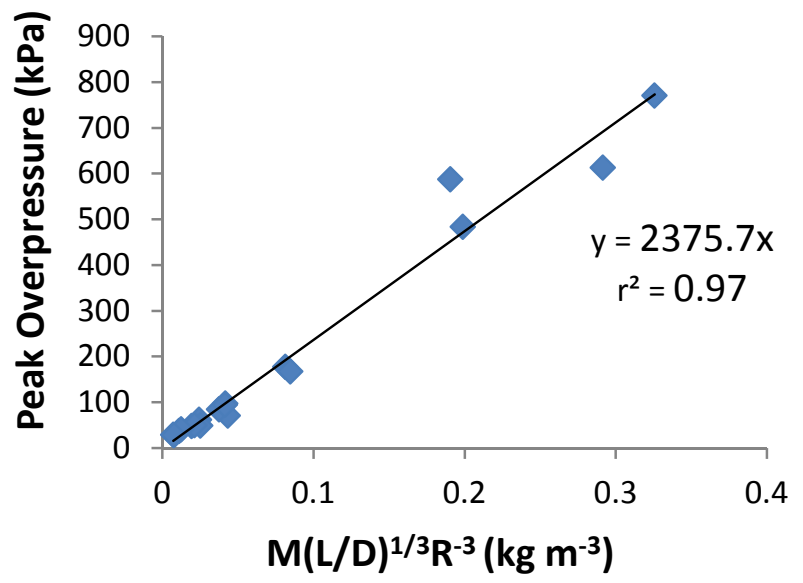

Figure 6. Peak overpressure plotted against $M(L / D)^{1 / 3} R^{-3}$ for cylinders, $L / D \geq 1$

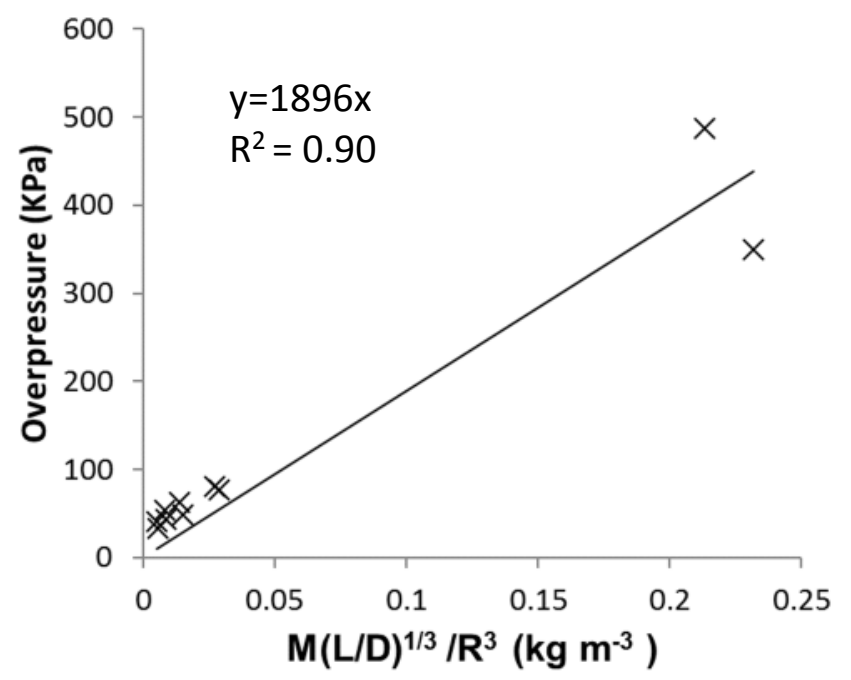

Figure 7. Peak overpressure plotted against $M(L / D)^{1 / 3} R^{-3}$ for discs, $L / D<1$.

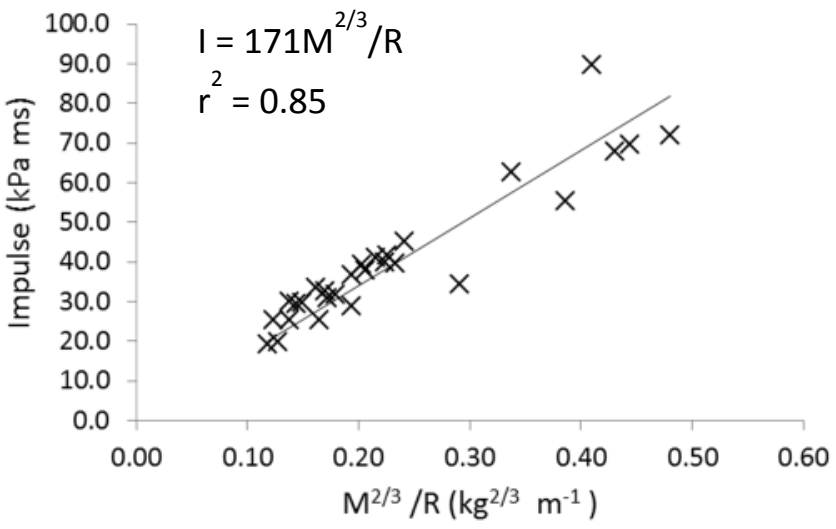

Figure 8. Impulse plotted against $\mathrm{M}^{2 / 3} \mathrm{R}^{-1}$ for $\mathrm{L} / \mathrm{D}$.
The results were also split into those for cylinders, $L / D \geq 1$, as in Figure 6 , and discs, $L / D<1$, in Figure 7. A better correlation is obtained for cylinders, $L / D \geq 1$ with $r^{2}=0.97$, than for all L/D ratios, $r^{2}=0.95$. For discs, $\mathrm{L} / \mathrm{D}<1$, the correlation decreases to $\mathrm{r}^{2}=0.9$.

The impulse was plotted using Eqn. (3). The equation gave a correlation coefficient of $\mathrm{r}^{2}=0.85$, Figure 8, with the constant $\mathrm{K}_{\mathrm{I}}=171 \mathrm{kPa} \mathrm{ms} \mathrm{mg}^{-2 / 3}$.

If an equation that included the length to diameter ratio was plotted, that is an equation of the form $\mathrm{I}=\mathrm{A} \mathrm{M}^{2 / 3}(\mathrm{~L} / \mathrm{D})^{\mathrm{n}} / \mathrm{R}$ where $\mathrm{n}$ and $\mathrm{A}$ are constants, no improvement in the correlation coefficient was observed.

\section{Discussion}

Experiments were carried out to study the double ended initiation of cylindrical charges of explosive. The results in the radial direction show that the peak overpressure depends on mass, distance and the length to diameter ratio. The relationship is given by Eqn. (6) namely

$$
\mathrm{P}=\mathrm{K}^{\prime} \frac{\mathrm{M}(\mathrm{L} / \mathrm{D})^{1 / 3}}{\mathrm{R}^{3}}=\mathrm{K}^{\prime} \frac{1}{Z^{3}}
$$

where $Z^{\prime}=R /\left(M^{1 / 3}(L / D)^{1 / 9}\right)$. $K^{\prime}$ is a constant and is equal to $2251 \mathrm{kPa} \mathrm{m}^{3} \mathrm{~kg}^{-1}$ for PE4.

When only cylinders are considered that is for a length to diameter ratio of greater or equal to 1 , L/D $\geq 1$, the correlation coefficient is $r^{2}=0.97$, Figure 6 . This compares to $r^{2}=0.95$ for all length to diameter ratios, Figure 3 . The correlation coefficient drops to $r^{2}$ $=0.9$ for discs when $\mathrm{L} / \mathrm{D}<1$, Figure 7 . This may be due to the small amount of data available close into the charge.

The relationship found for double ended initiation for the dependency of peak overpressure on mass, distance and the length to diameter ratio is the same as for single ended initiation [12]. This is the relationship given by Eqn. (6). The difference is that for single ended initiated charges the coefficient is $\mathrm{K}^{\prime}=$ $1525 \mathrm{kPa} \mathrm{m}^{3} \mathrm{~kg}^{-1}$ compares to $\mathrm{K}^{\prime}=2251 \mathrm{kPa} \mathrm{m}^{3} \mathrm{~kg}^{-1}$ for double ended initiation. This means that for double ended initiation the peak overpressure is 2251/1525 = 1.6 times that for single ended initiation.

To try to determine the mechanism behind the increase in peak overpressure for double ended initiation the scenario was modelled as two cylindrical charges end to end, Figure 9. In this instance each cylinder is detonated from one end and is half the size of the double ended initiated charge. Each half cylinder would then produce a shock wave that would collide along line $B$ in Figure 9.

Taking the $0.443 \mathrm{~kg}$ charge from this work, the $\mathrm{L} / \mathrm{D}$ ratio is 3.54 , length $0.168 \mathrm{~m}$ and diameter $0.047 \mathrm{~m}$. Dividing the charge into two, gives two cylinders of 
mass $0.222 \mathrm{~kg}, L / D=1.77$, length $0.084 \mathrm{~m}$, and diameter $0.047 \mathrm{~m}$.

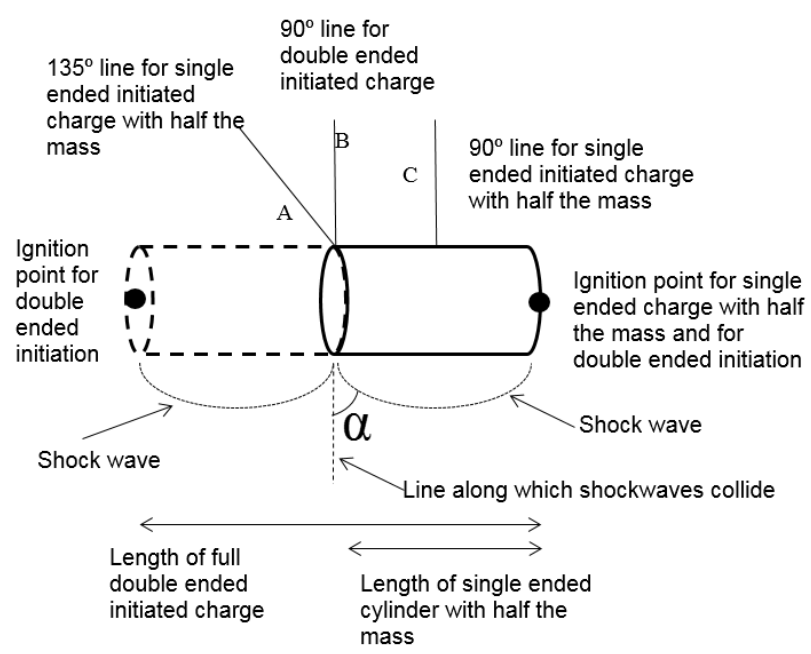

Figure 9. Modelling double ended initiation as two single ended initated cylinders. $\alpha$ is the angle at which the shock waves collide.

There is no data in the literature or collected by the authors that gives the peak overpressure along line B in Figure 9 for a single ended initiated cylinder. However published results show that for a single end initaion of a cylinder, the maximum peak overpressure from a cylinder $(L / D>1)$ occurs in the radial direction, along line $C$ in Figure 9 and decreases towards the corner [7], line A in Figure 9.

For the double ended initiation data presented in this paper the closest gauge to the charge was at $1 \mathrm{~m}$. This gives an angle of incidence for collision of the shock waves of $88^{\circ}$ and Mach reflection occurs. Eqn. (6) for single ended initiation gives $P=410 \mathrm{kPa}$, using $\mathrm{K}^{\prime}=1525 \mathrm{kPa} \cdot \mathrm{m}^{3} \mathrm{~kg}^{-1}$. At this incident pressure at $88^{\circ}$, the ratio of reflected pressure to incident pressure is less than 1.05 [2, figure 2-193]. This would give a reflected pressure of $430 \mathrm{kPa}$. The actual peak overpressure at $1 \mathrm{~m}$ for a mass of $0.443 \mathrm{~kg}$ for a double ended initiatied charge is $1520 \mathrm{KPa}$ using Eqn. (6) with $\mathrm{K}^{\top}=2251 \mathrm{kPa} \mathrm{m} \mathrm{kg}^{-1}$. This means that what is happening cannot be explained by the collision of the two shock waves after the shockwaves in air have been formed.

The impulse for single and double ended initiated charges are very similar, Figure 10 . If the data from the literature for single ended initiation [11] is limited to the data range available for the double ended initiated charges $\left(M^{2 / 3} / R<0.7 \mathrm{~kg}^{2 / 3} \mathrm{~m}^{-1}\right)$, then the results are indistinguishable, Figure 11. For single ended initiated charges the constant in Eqn.(3) is $\mathrm{K}_{\mathrm{I}}=$ $167 \mathrm{kPa} \mathrm{ms} \mathrm{m} \mathrm{kg}^{-2 / 3}$ and for double ended initiation $\mathrm{K}^{\circ}$, $=171 \mathrm{kPa} \mathrm{ms} \mathrm{m} \mathrm{kg}{ }^{-2 / 3}$.

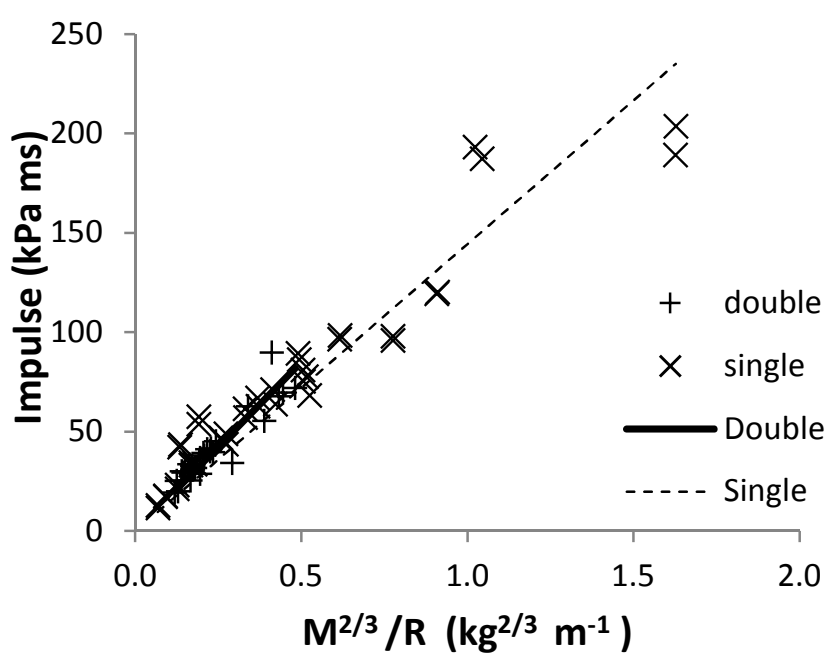

Figure 10. Impulse for double and single end initiated charges. For single ended initiation $I=144 \mathrm{M}^{2 / 3} / R$, with a correlation coefficient of $r^{2}=0.87$, for double ended initiation $\mathrm{I}=171 \mathrm{M}^{2 / 3} / R, \mathrm{r}^{2}=0.87$. Single ended detonation data from [11].

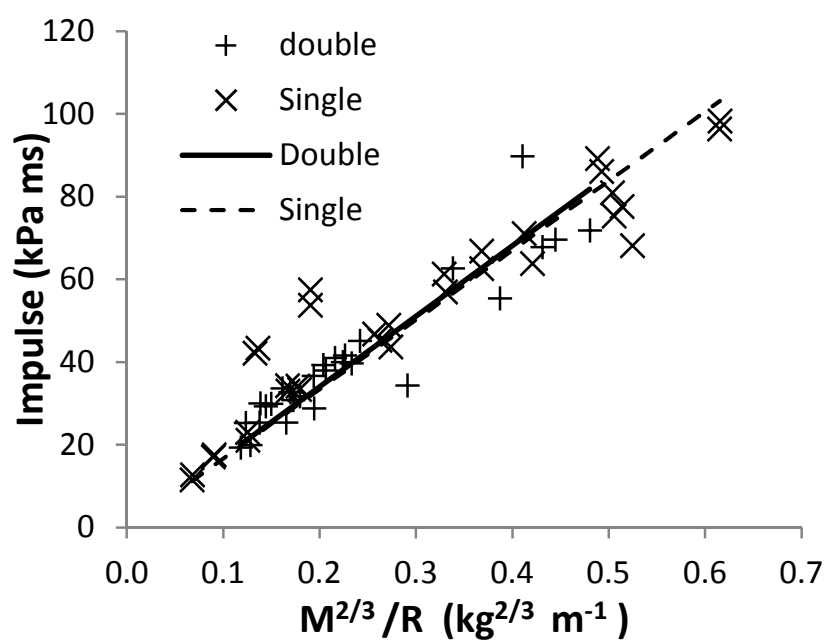

Figure 11. Impulse for double and end initiated charges, for only the data range of the double ended initiated charges. For single ended initiation $I=167$ $M^{2 / 3} / R$, with a correlation coefficient of $r^{2}=0.85$, for double ended initiation $\mathrm{I}=171 \mathrm{M}^{2 / 3} / \mathrm{R}, \mathrm{r}^{2}=0.87$. Single ended detonation data from [11].

This implies that the total impulse is unaffected by whether the charge is detonated from one end or both ends. Given that the total impulse in the radial direction is unaltered and the peak overpressure alters then it is the shape of the shock wave that is being altered.

This means that the shock wave produced by double ended initiation is being altered in shape by the collision of the detonation waves inside the charge. 


\section{Conclusions}

New data has been presented for the double ended initiation of cylindrical charges of explosive. The results in this paper showed that it is possible to predict the peak overpressure in the radial direction using the equation

$$
\mathrm{P}=\mathrm{K} \frac{\mathrm{M}(\mathrm{L} / \mathrm{D})^{1 / 3}}{\mathrm{R}^{3}}=\mathrm{K} \frac{1}{\mathrm{Z}^{3}}
$$

where $\mathrm{K}^{\top}=2251 \mathrm{kPa} \mathrm{m}^{3} \mathrm{~kg}^{-1}$. This is the same equation as for single ended initiation but with a different coefficient.

The data presented in this paper showed that the impulse in the radial direction can be predicted using

$$
\mathrm{I}=\mathrm{K}_{\mathrm{I}} \frac{\mathrm{M}^{2 / 3}}{\mathrm{R}}
$$

This is the same equation as for single ended initiation and the coefficients are very similar with $\mathrm{K}_{\mathrm{\prime}} \mathrm{=}$ $171 \mathrm{kPa} \mathrm{ms} \mathrm{m} \mathrm{kg}^{-2 / 3}$ for double ended initiation and $\mathrm{K}$ । $=167 \mathrm{kPa} \mathrm{ms} \mathrm{m} \mathrm{kg} \mathrm{m}^{-2 / 3}$ for single ended initiation (data from [11] adapted within this paper). Hence the impulse is not altered by the change of initiation system.

Comparing the results to single ended initiation then the peak overpressure has a coefficient $K^{\prime}$ that is 1.6 times that for single ended initiation. Hence the peak overpressure is 1.6 times that for single ended initiation. The impulse was found to be the same for double ended initiation as for single ended initiation. This means that when double ended initiation occurs it is the shape of the shock wave that is being altered.

\section{Symbols and Abbreviations}

L/D Length over diameter ratio of a cylinder

PE4 Flexible explosive containing 88\% RDX

SX2 Sheet explosive containing $88 \%$ RDX

RDX Cyclotrimethylenetrinitramine

$R \quad$ Distance from charge

$M \quad$ Charge mass

$\mathrm{K}^{\prime}, \mathrm{K}, \mathrm{K}_{\mathrm{I}}, \mathrm{K}_{\mathrm{l}}, \mathrm{a}, \mathrm{b}, \mathrm{c}, \mathrm{A}, \mathrm{B}, \mathrm{C}$ are explosive dependent constants

\section{Acknowledgements}

The authors would like to thank Dr Nigel Davies for his help and A.C. Anastacio would like to thank the Brazilian Army for their sponsorship.

\section{References}

[1] Fundamentals of protective design for conventional weapons, Report TM 5-855-1, US Army. Also known as Air force pamphlet AFPAM 32-1147 (I) and Navy manual NAVFAC (Naval facilities P-1080) and DSWA manual DAHSCWEMAN-97 1986

[2] Structures to resist the effects of accidnetal explosions. Unified Facilities Criteria. Report number UFC 3-340-02 2008

[3] Wisotski and W.H. Snyer, Characteristics of blast waves obtained from cylindrical high explosive charges. Report, University of Denver, Denver Research Institute, Denver, Colarado 80210, 1965

[4] W. C. F. Shepherd, Strength of High Explosives and Effects due to Shape, ch. 5 in: The Science of Explosives, (Eds.: C. E. H. Bawn, G. Rotter), Great Britain Advisory Council on Scientific Research and Technical Development, 1956, pp. 353.

[5] C. Knock, N. Davies, T. Reeves, Predicting blast waves from the axial direction of a cylindrical charge. Prop. Expl. Pyro. 2015, 40, 169-179.

[6] S.J. Schraml, R.L. Summers, R.M. Mudd, The influence of Initiator Configuration on Blast

Environments From Cylindrical Charges, 40th AIAA Aerospace Sciences Meeting and Exhibit, Reno, NV, USA, January 14-17, 2002, 1094.

[7] M. N. Plooster, Blast Effect From Cylindrical Explosive Charges: Experimental

Measurements,Report NWC TP 6382, Naval Weapons Center, China Lake, California, USA, 1982.

[8] E. D. Esparza, Spherical Equivalecy Of Cylindrical Charges In Free-air,25th Department of Defense Explosives Safety Seminar,Anaheim , USA, August 18-20, 1992

[9] C. Knock, N. Davies, Predicting the Peak Pressure from the Curved Surface of Detonating Cylindrical Charges, Prop Expl. Pyro. 2011, 36, 203 - 209.

[10] C. Knock, N. Davies, Blast waves from cylindrical charges,28th International Symposium on Shock Waves, Manchester, UK, July 18-22, 2011, p. 337 [11] C. Knock, N. Davies, Predicting the impulse from the curved surface of detonating cylindrical charges. Prop. Expl. Pyro. 2011, 36(2), 105-109.

[12] C. Knock, N. Davies, Blast waves from cylindrical charges, Shock Waves, 2013, 23, 337-342

[13] A. Keil, Measurements in shock waves in water with the high-speed spark camera, Report translation 213, United States Navy, Dtnisch-Nienhof, Germany, 1946.

Received: ((will be filled in by the editorial staff)) Revised: ((will be filled in by the editorial staff)) 
Full Paper

C. Author, B. Coauthor 